Bull. Mater. Sci., Vol. 8, No. 3. June 1986, pp. 379--384. (c) Printed in India.

\title{
R.F. magnetron sputtered tungsten carbide thin films
}

\author{
P K SRIVASTAVA, V D VANKAR and K L CHOPRA \\ Department of Physics and Centre for Materials Science and Technology, Indian Institute of \\ Technology, New Delhi 110016, India
}

\begin{abstract}
Thin films of tungsten carbide have been deposited on stainless steel substrates held at $500^{\circ} \mathrm{C}$ by r.f. reactive magnetron sputtering in two different modes of introducing argon and acetylene gases called normal and high rate mode. A single phase foc-WC is formed in the normal mode whereas a mixture of $A-15-W_{3} C$, hexagonal-WC and graphitic- and diamondcarbon is found in the high rate mode. A microhardness value as high as $3200 \mathrm{kgf} / \mathrm{mm}^{2}$ (as compared to the bulk value of $1800 \mathrm{kgf} / \mathrm{mm}^{2}$ ) is obtained in the film deposited by normal mode.
\end{abstract}

Keywords. Tungsten carbide; magnetron sputtering

\section{Introduction}

High rate reactive magnetron sputtering process for thin film deposition is important for industrial applications. Several workers (Aronson et al 1980; Schiller et al 1984; Kaiza et al 1981) have developed such techniques to deposit thin films of various transition metal carbides, nitrides, oxides etc for wear-resistant and protective coatings on various substrates like cemented carbide tools, high speed steel, copper and copper alloys. Efforts to enhance the deposition rate by effective control of the flow of reactive gases into sputtering chamber have been made. The processes that occur on the magnetron target surface are dependent on the interaction between sputter products and reactive gaseous products as well as on the degree of coverage of the reaction products obtained on the target. Generally in reactive sputtering, the target metal gets carburized, nitrided or oxidized by the reactive gases and subsequently sputtered at low rates since the sputtering yield for carbides, nitrides or oxides is much lower than those of the corresponding metals. Schiller et al (1980) deposited various compounds with very high rates by using a dc magnetron-plasmatron system in such a way that practically complete separation of solid component sputtering at the target and of the reaction of the produced particles with the gaseous component during condensation occurs on the substrate. They were able to sputter various compounds with very high rate $\left(\sim 1 \mu \mathrm{m} / \mathrm{min}\right.$ for $\left.\mathrm{Ta}_{2} \mathrm{O}_{5}\right)$. Recently Scherer and Wirz (1984) used a similar configuration for sputtering of $\mathrm{Al}_{2} \mathrm{O}_{3}$.

We have prepared tungsten carbide films by reactive r.f. magnetron sputtering on stainless steel substrates. The subst rate temperature, flow of gases and bias potential of the cathode were controlled to obtain hard adherent coatings. Two different modes of introducing argon and acetylene gases were studied. In one, called the normal mode (NM), the two gases were homogeneously mixed in the plasma region whereas in the other, called the high rate mode (HRM), separate zones of argon and acetylene were created by controlling the flow of the two gases such that the carbide formation on the 
tungsten target could be reduced (Srivastava et al 1985). The $\mathrm{WC}_{X}$ films formed in both the modes were analyzed by x-ray diffraction (XRD) and Auger electron spectroscopy (AES) for their structure and compositional analysis. The microhardness was measured by Vicker's microhardness tester fitted onto Carl Zeiss optical microscope. The indents produced during the microhardness measurements were also analyzed in a scanning electron microscope (SEM).

\section{Experimental details}

Figure 1 shows the magnetron sputtering system used for deposition of tungsten carbide films on stainless steel substrates held at $500^{\circ} \mathrm{C}$ in the normal mode (a) and in the high rate mode (b). Preparation of substrates for deposition and various conditions for sputtering is reported elsewhere (Srivastava et al 1984). Flow rates of argon and acetylene gases were maintained at $30 \mathrm{scc} / \mathrm{min}$ and $6 \mathrm{scc} / \mathrm{min}$, respectively for both systems. An r.f. power density of 4.5 watt $/ \mathrm{cm}^{2}$ was maintained during sputtering. This developed a target bias voltage of 500 volts. For each run, the substrate temperature, flow of gases and the bias potential developed on the cathode were kept constant. Under similar conditions the deposition rate of tungsten films and tungsten carbide films in normal and high rate mode are 825,600 and $825 \AA / \mathrm{min}$ respectively.

An x-ray diffractometer (Philips PW 1730/10) was used for $\mathrm{x}$-ray analysis in $\theta-2 \theta$ scan mode using $\mathrm{CuK}_{a_{1}}(1.54 \AA)$ radiation and $1^{\circ} / \mathrm{min}$ scan speed. For compositional analysis, a scanning Auger microprobe (PH1 590) with electron beam of $0.2 \mu \mathrm{m}$ diameter was used. The sputter depth profile was performed with an ion gun of $\sim 200 \mu \mathrm{m}$ diameter operated at $5 \mathrm{kV}$ and current density $600 \mu \mathrm{A} / \mathrm{cm}^{2}$.

\section{Results and discussion}

Figure 2 shows the XRD profiles for $4.2 \mu \mathrm{m}$ thick films deposited at $500^{\circ} \mathrm{C}$ in the normal mode (a) and in the high rate mode (b). The maximum grain size as calculated from the broadening of $x$-ray peaks is $\sim 300 \AA$ for both types of films. Since at different temperatures the structure and composition of the film are different, correlation of the grain size variation with temperature is not possible. The interplanar spacings $d$ were calculated from the XRD and compared with standard data (ASTM data cards). The NM films deposited at $500^{\circ} \mathrm{C}$ on stainless steel are cubic tungsten monocarbide (f.c.c. B1 structure) while the HRM films deposited at $500^{\circ} \mathrm{C}$ are a mixutre of various phases, namely $\mathrm{A}-15 \mathrm{~W}_{3} \mathrm{C}$, hexagonal WC, graphitic carbon and diamond carbon.

Figure (3a) shows the AEs traces of the surface of $\mathrm{WC}_{X}$ films which is a typical feature of all the films sputtered in both modes. Oxygen $\left(\mathrm{KL}_{2,3} \mathrm{~L}_{2,3}-512 \mathrm{eV}\right)$ is a major impurity on the surface. The presence of carbon is indicated by a peak $\left(\mathrm{KL}_{2,3} \mathrm{~L}_{2,3}\right.$ $271 \mathrm{eV}$ ) which has a characteristic shape suggesting the formation of graphitic phase on the surface. Inside the bulk of the NM film the shape of this peak changes and additional features at $252 \mathrm{eV}$ and $260 \mathrm{eV}$ appear (figure 3b). Such features are characteristic of carbide phase formation (Moyoshi and Bucklay 1982). Similar peaks at $252 \mathrm{eV}$ and $260 \mathrm{eV}$ appear in the HRM films but these peaks are not very sharp suggesting that the carbide phase formation is not complete and a mixture of graphitic and carbidic phases are present (figure 3c). Thus XRD and AES profiles are found consistent with each other. AES 


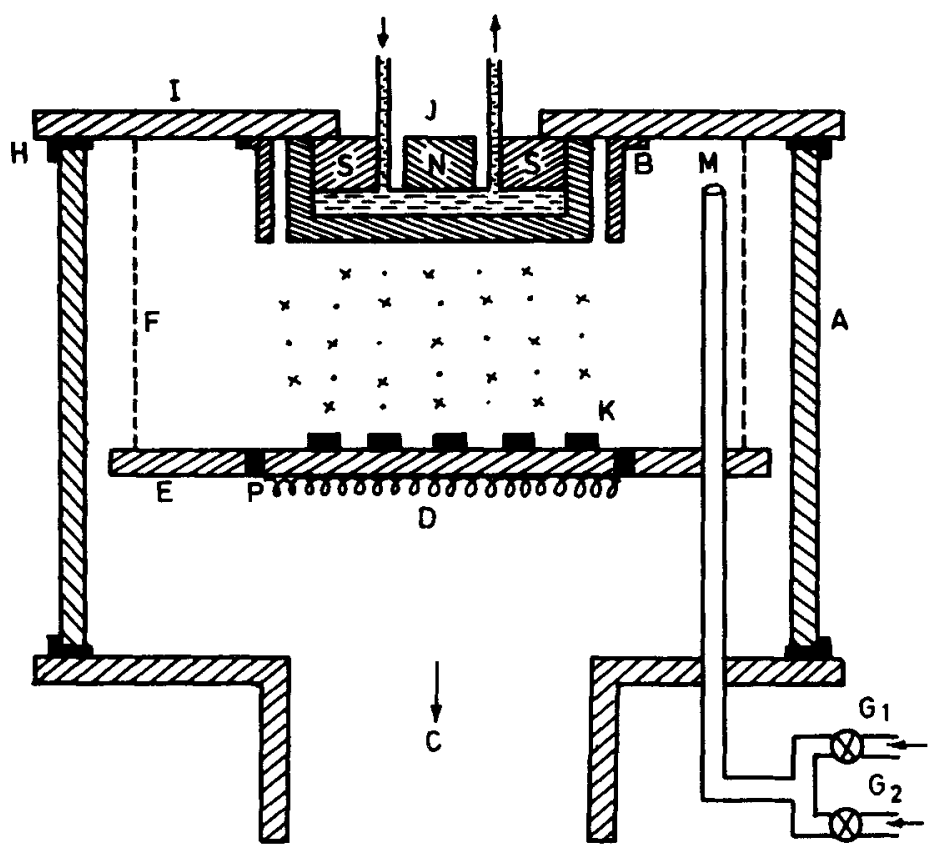

(a)

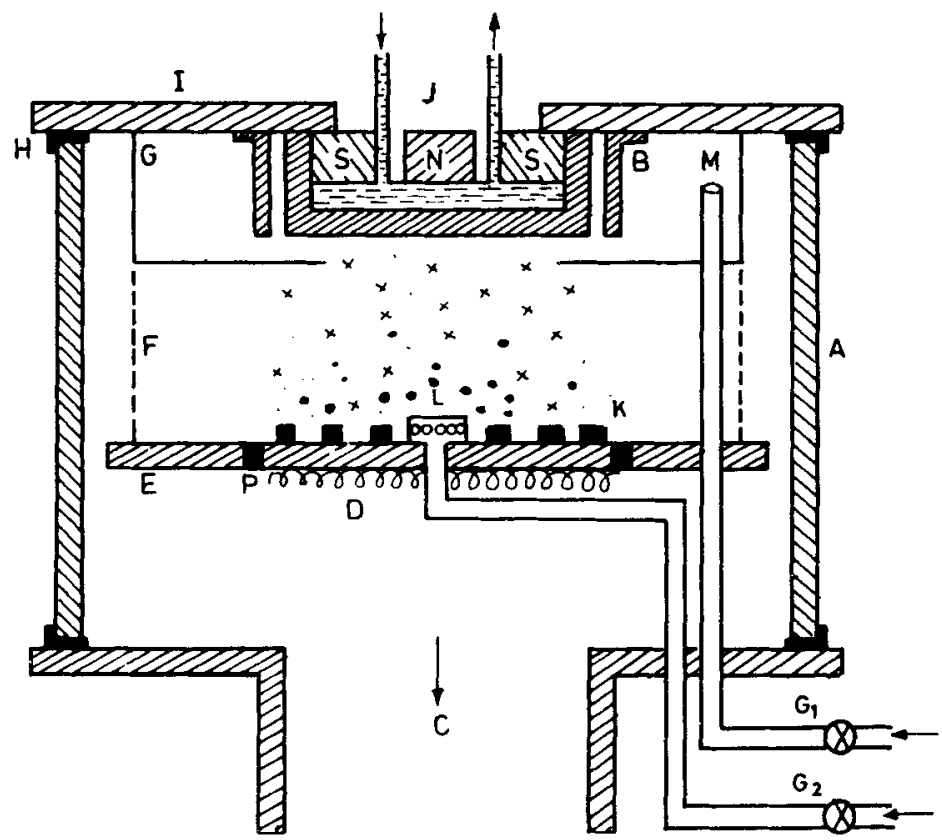

(b)

Figure 1. Schematic diagram of reactive r.f. magnetron system in (a) normal mode, (b) high rate mode showing metallic belljar $(A)$, target shield $(B)$, vacuum pump $(C)$, subs trate heater $(D)$, grounded base plate $(E)$, perforated aluminium mesh $(F)$, aluminium metall c partition $(G)$, $\mathrm{L}$ gasket for vacuum sealing $(\mathrm{H})$, top plate $(\mathrm{I})$, target $(\mathrm{J})$. substrate $(\mathrm{K})$, openin $\lesseqgtr$ of reactive gas (L), opening of inert gas $(M)$, insulator ring ( $P$ ), and precision needle valve; $\left(G_{1}\right.$ and $\left.G_{2}\right)$. 


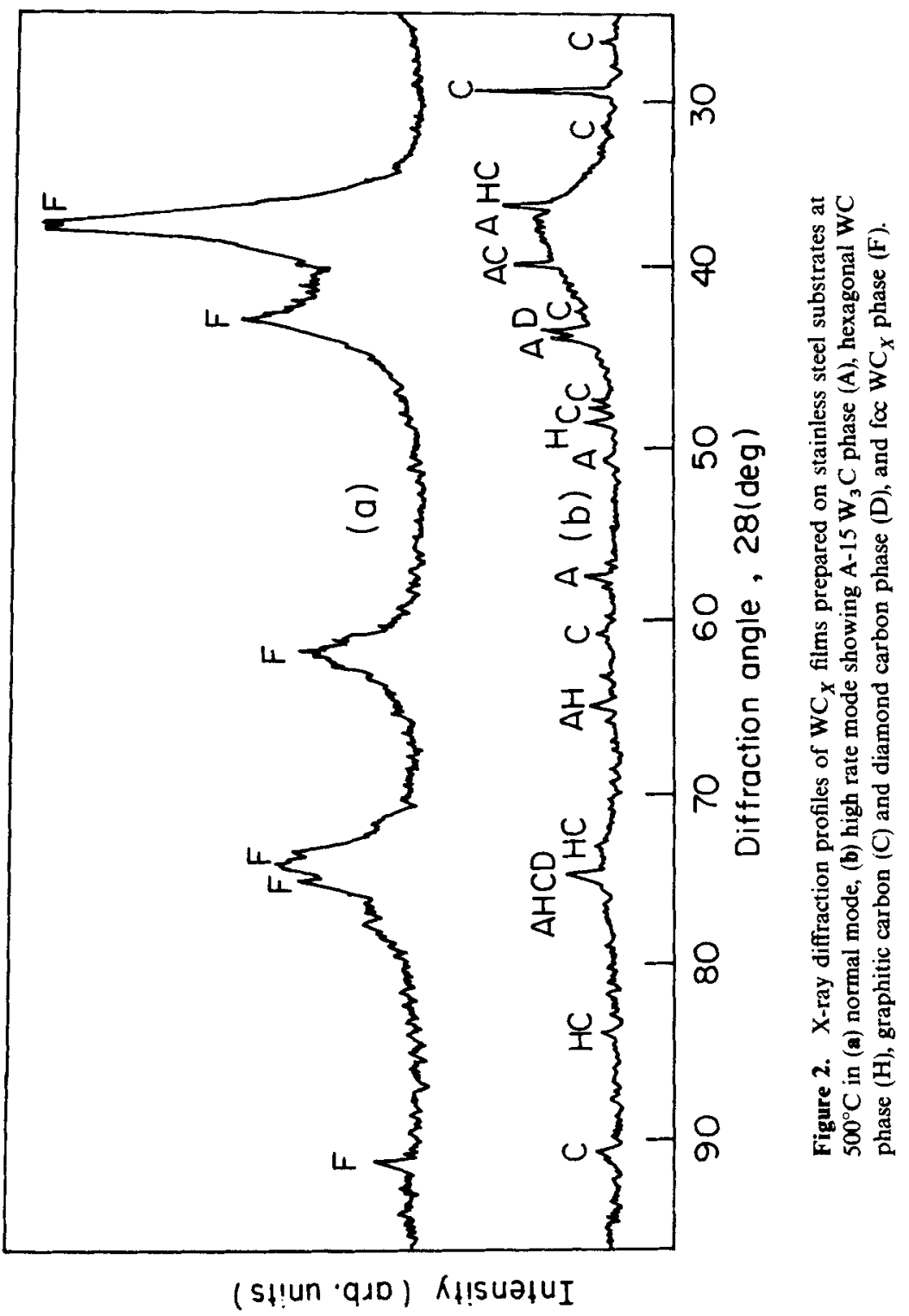




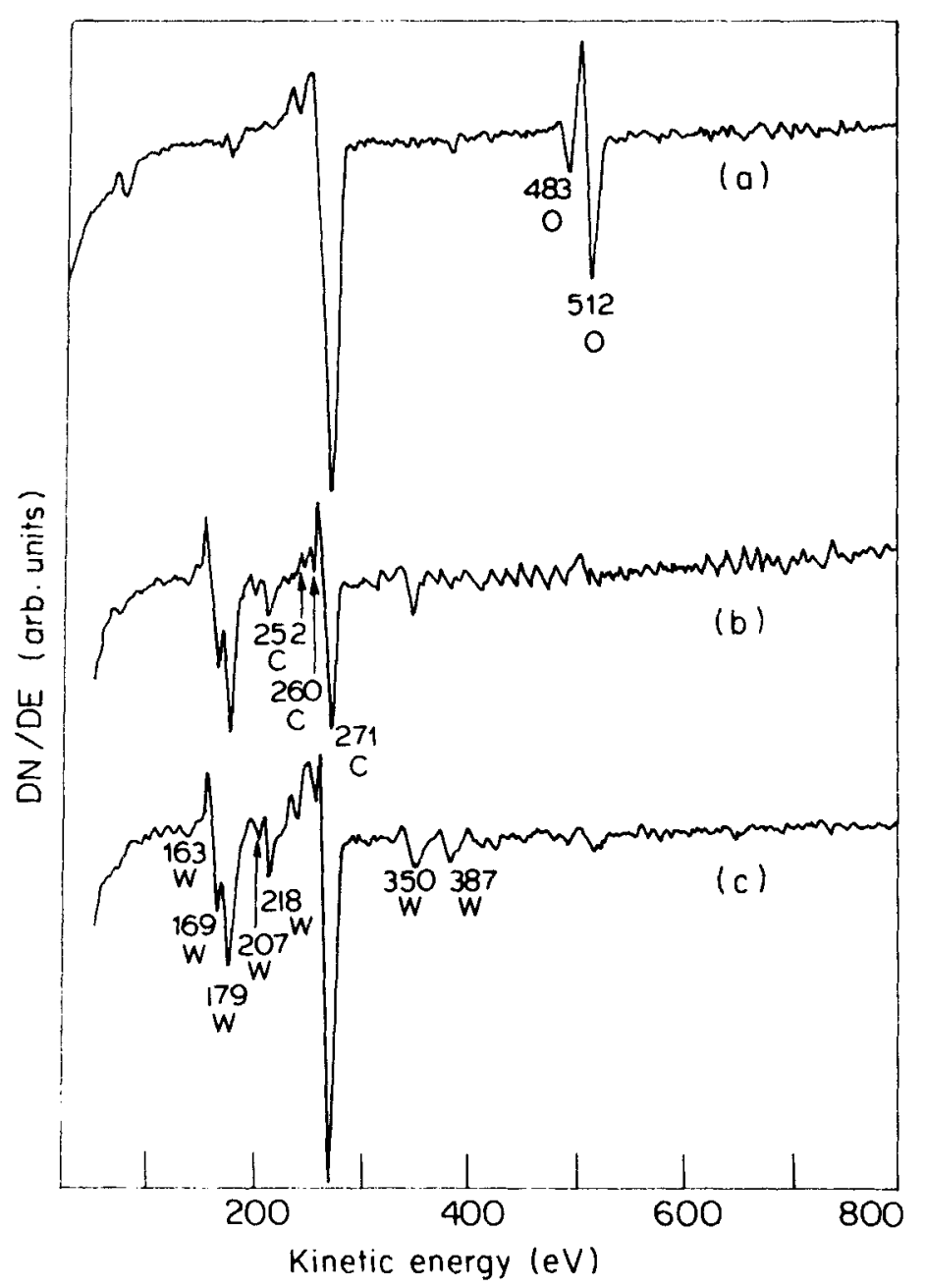

Figure 3. AES profile of $W_{X}$ films deposited at $500^{\circ} \mathrm{C}$ on stainless steel substrate at (a) and surface of HRM films, (b) $100 \mathrm{~A}$ depth from the surface of NM films, and (c) $100 \mathrm{~A}$ depth from the surface of HRM films.

analysis yields the composition of these films as $50 \% \mathrm{~W}, 50 \% \mathrm{C}$ for $\mathrm{NM}$ films, and $40 \%$ $\mathrm{W}, 60 \% \mathrm{C}$ for HRM films.

The microhardness of the films has been measured by Vicker's microhardness indentor and value of 3200 and $2365 \mathrm{kgf} / \mathrm{mm}^{2}$ is observed at $10 \mathrm{~g}$ load for NM and HRM films respectively. It should be noted that the bulk hardness of tungsten carbide (hexagonal phase) is $1800 \mathrm{kgf} / \mathrm{mm}^{2}$. The higher values observed in NM films may be due to fine grain size and B1 fcc crystal structure. HRM films crack during the microhardness measurement and a circular crack pattern is developed around the indentation. The number of the cirlces increases with increasing load and three concentric circles are formed at a load of $160 \mathrm{~g}$. In the case of NM films such cracks around the indentation are not observed.

The XRD and AES studies suggest that the HRM films have excess free carbon in graphitic and diamond form which is dispersed in $\mathrm{W}_{3} \mathrm{C}$ (A-15 phase) and WC (hexagonal 
phase) resulting in brittle films (as observed in microhardness measurements) which develop cracks at higher loads. On the other hand, NM films have single phase and are less brittle and, therefore, do not crack at loads as high as $160 \mathrm{~g}$.

\section{Conclusions}

(i) Rates of deposition of $\mathrm{WC}_{X}$ films as high as that of pure tungsten have been achieved by dividing the inert and reactive gases in separate zones and controlling their flow patterns in such a way that the carbide formation on target surface is avoided.

(ii) $\mathrm{W}_{3} \mathrm{C}$ (A-15 phase), WC (hexagonal) and carbon (graphitic and diamond form) are obtained in the films prepared in the modified geometry whereas in the normal geometry a single phase fcc tungsten monocarbide is formed.

(iii) A microhardness value as high as $3200 \mathrm{kgf} / \mathrm{mm}^{2}$ at $10 \mathrm{~g}$ load has been obtained in single phase fcc $\mathrm{WC}_{X}$ films whereas the films containing a mixture of phases and dispersed carbon have lower microhardness $\left(2365 \mathrm{kgf} / \mathrm{mm}^{2}\right)$ at $10 \mathrm{~g}$ load.

\section{Acknowledgements}

The authors are grateful to the Department of Science and Technology, New Delhi, for financial support, to Dr K C Nagpal for help and advice with $\mathrm{x}$-ray diffraction work, to M Bhatnagar for AES work, to Vandana Agrawal and R S Rastogi for technical discussion.

\section{References}

Aronson A J, Chen D and Class W H 1980 Thin Solid Films 72535

ASTM Data Card Nos. 20-1316, 5-728, 22-1069, 6-675

Kaiza K, Tsunetaka S and Mitsunori K 1981 Thin Solid Films 7841

Moyashi and Bucklay D H 1982 Appl. Surf. Sci. 10357

Scherer M and Wirz P 1984 Thin Solid Films 119203

Schiller S, Heisig U, Strumptel K and Sieber W 1980 Vakuumtechnik 301

Schiller S, Beister G and Sieber W 1984 Thin Solid Films 111259

Srivastava P K, Rao T V, Vankar V D and Chopra K L 1984 J. Vac. Sci. Technol. A2 1261

Srivastava P K, Vankar V D and Chopra K L 1985 J. Vac. Sci. Technol. A3 2129 